\title{
Infrared Spectroscopic Study on a Reaction of Hydrogen Plasma with Si(110) surface
}

\author{
Masanori Shinohara*, Ko-jiro Hara, Yoshiki Takami, Yu-ya Takaki, \\ Yoshinobu Matsuda, and Hiroshi Fujiyama, \\ Graduate School of Engineering, Nagasaki University, 1-14 Bunkyo Nagasaki, 852-8521, Japan \\ *Fax: 81-95-819-2542, e-mail: sinohara@nagasaki-u.ac.jp
}

\begin{abstract}
The reaction of hydrogen plasma with $\mathrm{Si}(110)$ surface was investigated at the floating condition. The evolution of hydride components in $\mathrm{Si}(110)$ were monitored with the infrared absorption spectroscopy in multiple internal reflection geometry (MIR-IRAS). IR data indicate that the surface was terminated with hydrogen by the exposure to hydrogen plasma, and also indicate that the atomic arrangements of $\operatorname{Si}(110)$ surface were distorted, then abundant parts of the surface were changed in amorphous phase with forming dihydride. However, characteristic structures of -Si-Si- chains on crystalline (110) face were retained.
\end{abstract}

Key words: hydrogen, plasma, Si (110), hydride components, floating

\section{INTRODUCTION}

Hydrogen plasma generates hydrogen radicals and ions in it. Both of them are important to Si technologies, such as the deposition of Si-related films, the etching of the films, and so on. Then, there have been many reports about interactions between hydrogen and Si surface so far. Hydrogen radicals generate the adsorption sites by abstracting hydrogen from hydrogen terminated $\mathrm{Si}$ surface $^{1-3}$. Hydrogen radicals terminated dangling bonds of Si films ${ }^{4-7}$. Hydrogen ions also play an important role in $\mathrm{Si}$ etching process. For example, hydrogen and hydrogen-containing gas such as hydrogen bromide $(\mathrm{HBr})$ are used for etching $\operatorname{gas}^{8-9}$. On the other hand, high-energy hydrogen ions give damages to a $\mathrm{Si}$ crystal $^{10-13}$. The damages have a relation with the crystal orientation ${ }^{14}$. One of the famous defects is the hydrogen platelet defects in Si crystal, which were formed in the $<111>$ direction of by the diffusion of hydrogen into Si. It indicated the hydrogen diffusion stopped in the <111> direction ${ }^{15}$. Then, the [110] face is very curious orientation. This is because the $\mathrm{Si}(110)$ surface has interesting atomic arrangements; when we look at the $\mathrm{Si}$ crystal lattice in the $\langle 110\rangle$ direction of Si crystal, we can

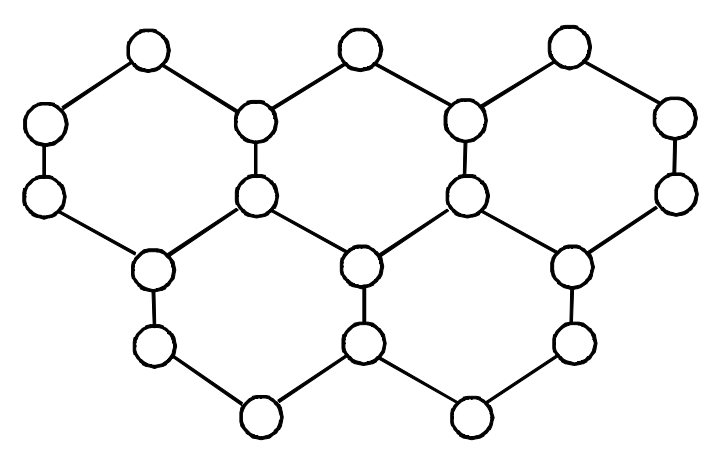

Fig. 1 Schematic of atomic arrangement of (110) face of Si crystal viewed along [110] direction. get unobstructed views of the hexagonal openings among $\mathrm{Si}$ atoms, as shown in Fig. 1. The opening is larger than a hydrogen atom. We expect hydrogen would easily insert into $\mathrm{Si}$ crystal.

Controlling the behavior of hydrogen on a Si surface is one of the keys for improvements of Si processing. This is because the plasma induced surface reactions are the frontier of both of the film deposition and film etching processes. To control them, we have to know the detailed the surface reactions of hydrogen. Moreover, controlling hydrogen plasma process will lead to the suppression of the Si damages. Then, the reaction process of hydrogen plasma with $\mathrm{Si}(110)$ surface should be understood in details at an atomic level.

Thereby, we investigated the hydrogen plasma induced Si (110) surface reaction. An "in-situ" monitoring method is required for the understanding of the surface reaction, because the surface will be easily changed due to oxidation during the transportation of the sample from the processing chamber to the ex-situ measurement apparatus. Furthermore, another vacuum system will be installed to the processing chamber in order to use "in-situ" surface analysis methods such as photoelectron spectroscopy and so on, because plasma is generally generated in a low pressure. Then, there are not so many surface analysis methods applied for plasma induced surface reactions. One of promising observation methods is infrared absorption spectroscopy in multiple internal reflection geometry (MIR-IRAS) ${ }^{16}$. This method can be applied for "in-situ" measurements, irrespective of environments around the prism, such as pressure and mediums ${ }^{6-7,17-20}$. Moreover, this method has high detection sensitivity and a high resolution, so that the adsorption structure can be detected in sub-monolayer level ${ }^{21-22}$.

\section{EXPERIMENTS}

We used stainless steel chamber ${ }^{18-19}$ for plasma induced surface reaction analysis. The chamber was equipped with an IRAS monitoring system, as shown in Fig. 2. The chamber has radio frequency $(13.56 \mathrm{MHz})$ plasma source, gas delivery system, and vacuum pumping system. Plasma was generated by using a RF 


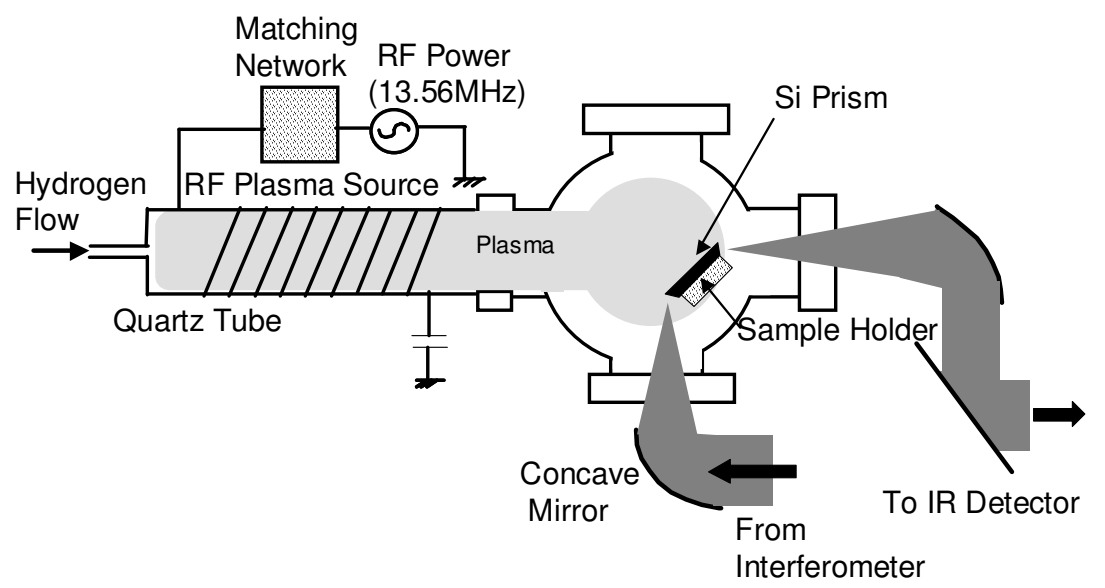

Fig. 2 Experimental setup

power to a coil wrapped around a quartz tube with a diameter of $3 \mathrm{~cm}$. The inlet gases were fed through the glass tube. The flow rate of hydrogen gas was controlled by a mass flow controller. The base pressure of the chamber was maintained below $2 \times 10^{-4} \mathrm{~Pa}$.

The Si prisms were used as MIR prisms in this study. The Si prisms of $10 \times 40 \times 0.5 \mathrm{~mm}$ were produced from n-type P-doped, and both-side polished $\mathrm{Si}(110)$ wafers with the resistivity of approximately $10 \Omega \mathrm{cm}$. The $\mathrm{Si}$ prisms were cleaned with the conventional RCA cleaning before introducing into them the chamber. The Si prisms were covered with the chemical oxide, which produced in boiled $\mathrm{H}_{2} \mathrm{SO}_{4} / \mathrm{H}_{2} \mathrm{O}_{2}$ solution. The chemical state of the surface was monitored using the MIR-IRAS technique. Infrared radiation from an interferometer was focused at normal incidence onto one of the two bevels of the sample; the light traveled through the wafer with internal reflections at the substrate surface. The radiation that exited the sample from the other bevel was focused onto a liquid- $\mathrm{N}_{2}$-cooled mid-band $\mathrm{HgCdTe}$ (MCT) detector.

The chemical oxide-covered surface is used for the starting surface in this study. The spectrum of the chemical oxide-covered surface was used as a reference spectrum, because the oxide film contains little $\mathrm{Si}-\mathrm{H}$ bonds ${ }^{23}$. Then, we can monitor the formation of $\mathrm{Si}-\mathrm{H}$ bonds due to the exposure of the Si surface to hydrogen plasma. The hydrogen plasma was generated in the hydrogen pressure of $6.7 \mathrm{~Pa}$ by supplying $30 \mathrm{~W}$ RF power. The Si prism was placed with electrically floating condition on the sample stage located inside the chamber.

\section{RESULTS AND DISCUSSION}

Figure 3 shows infrared absorption spectra in the $\mathrm{Si}-\mathrm{H}$ stretching vibration region observed for the $\mathrm{Si}(110)$ surface that was exposed to hydrogen plasma at room temperature for different exposure times. In the bottom of Fig. 3 we show an IRAS spectrum of the HF-treated surface for a comparison to other spectra. The HF-treated $\mathrm{Si}$ surface is covered with hydrogen. The spectrum showed intense peaks at $2070 \mathrm{~cm}^{-1}$ and at $2089 \mathrm{~cm}^{-1}$, which is attributed to monohydride components. It also has a peak around $2100-2110 \mathrm{~cm}^{-1}$ due to dihydride
$\left(\mathrm{SiH}_{2}\right)$ components and a peak at $2140 \mathrm{~cm}^{-1}$ due to $\mathrm{SiH}_{2}$ components on the steps ${ }^{24}$. The ideal HF-treated $\mathrm{Si}(110)$ surface is monohydride $(\mathrm{SiH})$ terminated surface. Two $\mathrm{Si}-\mathrm{H}$ stretching vibration modes due to $-\mathrm{SiH}-\mathrm{SiH}$ - zigzag chains are observed at 2070 and $2089 \mathrm{~cm}^{-1}$. The former is due to the out-of-phase vibration mode, and the latter is due to the in-phase vibration mode of the - $\mathrm{SiH}-\mathrm{SiH}-$ chains. The peak at $2070 \mathrm{~cm}^{-1}$ has much higher intensity than the peak at $2089 \mathrm{~cm}^{-1}$, especially the former peak has 3 times larger intensity than the latter peak in this surface.

We cannot observe any peaks until the hydrogen

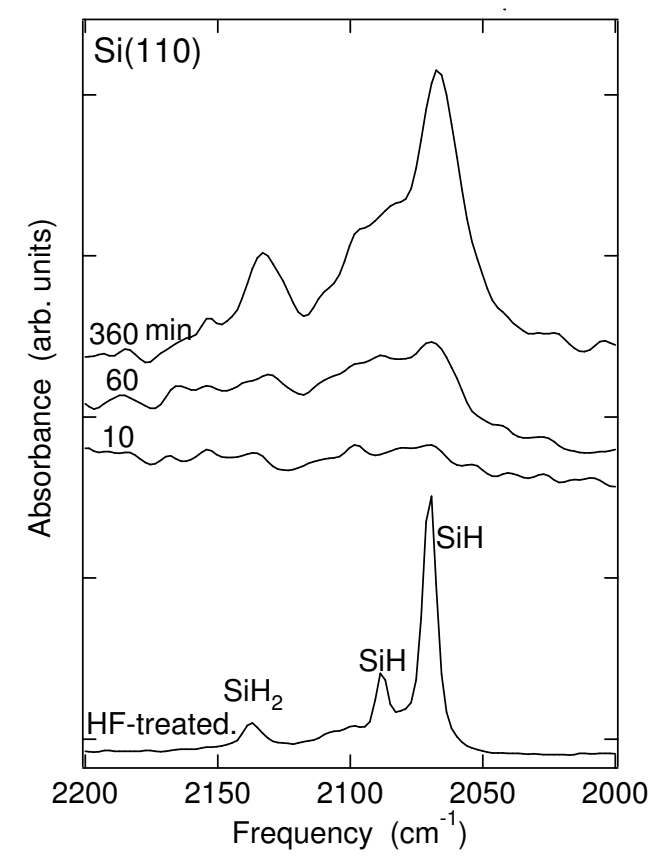

Fig. 3 Infrared spectra of the chemical oxide covered $\mathrm{Si}(110)$ surface exposed to hydrogen plasma at floating condition. 
plasma exposure for $10 \mathrm{~min}$. It means that it takes $10 \mathrm{~min}$ to etch the chemical oxide layer with which the Si surface was covered. Of course, some of hydrogen atoms can penetrate the oxide layer to form the $\mathrm{Si}-\mathrm{H}$ bonds, but the oxide layer would be etched by the exposure to hydrogen plasma for $10 \mathrm{~min}$. We can observe the peak at $2098 \mathrm{~cm}^{-1}$ and a broad peak between 2080 and $2060 \mathrm{~cm}^{-1}$ in the spectrum of the surface exposed to hydrogen plasma for $10 \mathrm{~min}$. Here, the peaks at $2098 \mathrm{~cm}^{-1}$ were not observed on the HF-treated $\mathrm{Si}(110)$ surface. Then, the new components should be generated by the hydrogen plasma exposure. From the peak position, this peak at $2098 \mathrm{~cm}^{-1}$ is attributed to $\mathrm{SiH}_{2}$, which is frequently observed in amorphous silicon film. The peak at $2082 \mathrm{~cm}^{-1}$ can be attributed to the $\mathrm{SiH}$ on the $\mathrm{Si}$ surface. The peak position is close to $\mathrm{SiH}$ on the HF-treated $\mathrm{Si}(100)$, which has a peak at $2086 \mathrm{~cm}^{-1} 18,25$. It indicated the atomic arrangement of the $\mathrm{Si}$ surface was distorted by the exposure to hydrogen plasma even for $10 \mathrm{~min}$; and abundant parts of the surface became atomically rough and amorphous.

The peak at approximately $2067 \mathrm{~cm}^{-1}$ was increased with the exposure to hydrogen plasma. The peak is close to the above-mentioned peak located at $2070 \mathrm{~cm}^{-1}$, due to the out-of-phase vibration mode of $-\mathrm{SiH}-\mathrm{SiH}$ - zigzag chains on the HF-treated $\mathrm{Si}(110)$ surface. We have to observe the other peak at $2089 \mathrm{~cm}^{-1}$, in order to assign to the peak due to $-\mathrm{SiH}-\mathrm{SiH}$ - chains on the HF-treated $\mathrm{Si}(110)$ surface. The peak at $2089 \mathrm{~cm}^{-1}$ was exhibited in the spectrum observed for the 360-min exposure surface. However, the peak intensity located at $2089 \mathrm{~cm}^{-1}$ is relatively strong compared with the peak at $2068 \mathrm{~cm}^{-1}$, dissimilar of the peak on HF-treated $\mathrm{Si}(110)$ surface. Moreover, these both peaks were broad, in comparison with those observed in the HF treated $\mathrm{Si}(110)$ surface. It means that the characteristic structures of -Si-Si- zigzag chains on crystalline (110) face remains after the plasma exposure. Moreover, it also indicates that the back bonds of the mentioned -Si-Si- zigzag chains have a lot of the chemical states; the back bonds would be bound to the amorphous portions. The amorphous components have a lot of bonding states, i.e. a lot of bonding angle, bonding distances and so on. These slight different bonding states will give slight changes to the $\mathrm{SiH}$ peak position, and then half-hand width of the mentioned $\mathrm{SiH}$ peak became broad. It is suggested that the differences in the spectral features between hydrofluoric acid treatments and hydrogen plasma exposures come in reaction depths regarding penetration of gaseous hydrogen atom. Then, we will investigate the reaction depth in the plasma exposure, in the near future. As described in the former section, the amorphous layer was formed due to the hydrogen plasma exposure. Furthermore, the peak due to $\mathrm{SiH}_{2}$ in the amorphous layer and that due to $\mathrm{SiH}$ on the surface layer should be overlapped in these regions around $2090 \mathrm{~cm}^{-1}$. Then, these indicate that the atomic arrangements of the [110] face were not completely destroyed, although the abundant parts of the surface were partly distorted to be amorphous.

The other peak was observed at $2133 \mathrm{~cm}^{-1}$ after the exposure to hydrogen plasma for more than $60 \mathrm{~min}$. The peak can be assigned to $\mathrm{SiH}_{3}$, because of existence of steps, kinks, hillocks and so on. However the $\mathrm{SiH}_{3}$ is not suggested stable during hydrogen plasma; $\mathrm{SiH}_{3}$ would be easily decomposed to $\mathrm{SiH}_{2}$ and $\mathrm{SiH}$. The peak at 2133 $\mathrm{cm}^{-1}$ was also increased with the hydrogen plasma exposure, especially after the exposure for $360 \mathrm{~min}$, as the peak at $2067 \mathrm{~cm}^{-1}$ was increased. Then, the peak has a relation with the peak at $2067 \mathrm{~cm}^{-1}$. Then, the peak can be attributed to the $\mathrm{SiH}_{2}$ on the step of $\mathrm{Si}(110)$ surface, which is located at $2140 \mathrm{~cm}^{-124}$. However, the peak was relatively strong compared with the peak at $2068 \mathrm{~cm}^{-1}$, dissimilar of the HF-treated $\mathrm{Si}(110)$ surface. It indicates that a lot of steps were formed on the surface by the exposure. The peak can be observed at the initial stage, i.e. at the exposure for $10 \mathrm{~min}$. It indicates that the steps were formed at the initial stage of the plasma exposure. If the hydrogen plasma were attacked with more energy, the steps would be completely destroyed so that the surface would be completely amorphous. In this exposure condition, i.e. at a floating condition, the ion energy is not so high; as a result the atomic arrangements of the surface were not completely destroyed.

From this study, we found that hydrogen plasma leads the surface to be terminated with hydrogen and also the atomic arrangement of $\mathrm{Si}(110)$ surface to be distorted even in the early stage of the hydrogen plasma exposure; some parts of the surface become amorphous even in the initial stage. However, characteristic structures of -Si-Sichains on crystalline (110) face were retained in the surface even after the hydrogen plasma exposure for long time, i.e. for $360 \mathrm{~min}$, at the floating condition. Of course, abundant parts were changed into amorphous phase with forming dihydride components.

In this experiment we used the P-doped Si wafer. The impurities have a close relation with the hydrogen trap in semiconductor materials ${ }^{26}$. Thereby we will investigate the interaction between hydrogen plasma and B-doped wafer in the near future.

\section{CONCLUSION}

We investigated reactions of hydrogen plasma with $\mathrm{Si}(110)$ surface at the floating condition, with infrared absorption spectroscopy in multiple internal reflections geometry (MIR-IRAS). The results indicated that the $\mathrm{Si}$ surface was terminated with hydrogen by the hydrogen plasma exposure. Moreover, the results indicated the atomic arrangement of $\mathrm{Si}(110)$ surface was also distorted by the hydrogen plasma exposure; abundant parts of the surface became amorphous. However, the characteristic structures of -Si-Si- zigzag chains on crystalline [110] face were retained by the long exposure at the floating condition.

\section{ACKNOWLEDGMENTS}

The part of this study was supported by both of a Grant-in-Aid for Young Scientists (A), No. 20684027 (2008-2012) from the Ministry of Education, Culture, Sports, Science and Technology (MEXT) of Japan and a Grant-in-Aid for Scientific Research on Innovative Areas No. 22110511 (2010-2012) from MEXT of Japan.

\section{REFERENCE}

[1] A. Gupta, H. Yang, and G. N. Parsons, Surf. Sci. 496, 307-317 (2002).

[2] K. Sinniah, M.G. Sherman, L.B. Lewis, W.H. Weinberg, J.T. Yates, and K.C. Janda, J. Chem. Phys. 92, 5700-5711 (1990). 
[3] A. Dinger, C. Lutterloh, and J. Kuppers, Chem. Phys. Lett. 311, 202-208 (1999).

[4] Y. J. Chabal and K. Raghavachari, Phys. Rev. Lett. 54, 1055-1058 (1985).

[5] J.J. Boland, Surf. Sci. 261, 17-28 (1992).

[6] M. Niwano, M. Terashi, and J. Kuge, Surf. Sci. 420, 6-16 (1999).

[7] M. Terashi, J. Kuge, M. Shinohara, D. Shoji, and M. Niwano, Appl. Surf. Sci., 130-132, 260-265 (1998).

[8] M. C. Lemme, T. Mollenhauer, H. Gottlob, W. Henschel, J. Efavi, C. Welch, and H. Kurz, Microelectron. Eng. 73-74, 346-350 (2004).

[9] K. Ono, H. Ohta, and K. Eriguchi, Thin Solid Films 518, 3461-3468 (2010).

[10] G. Konac, S. Kalbitzer, Ch. Klatt, D. Niemann, and R. Stoll, Nucl. Instrum. Methods B 136-138, 159-165 (1998).

[11] Y.J Chabal, M.K Weldon, Y Caudano, B.B Stefanov and K Raghavachari, Physica B 273-274, 152-163 (1999).

[12] O.W. Holland, J. D. Budai, and B. Nielsen, Mater. Sci. Eng. A 253, 240-248 (1998).

[13] T. Höchbauer, A. Misra, R. Verda, Y. Zheng, S. S. Lau, J. W. Mayer, and M. Nastasi, Nucl. Instrum. Methods B 175-177, 169-175 (2001).

[14] N.M. Johnson, F.A. Ponce, R.A. Street, and R.J. Namanich, Phys. Rev. B 35, 4166-4169 (1987).
[15] K.H. Hwang, E. Yoon, K.-W. Whang, and J.Y. Lee, Appl. Phys. Lett. 67, 3590-3592 (1995).

[16] Y.J. Chabal, Surf. Sci. Rep. 8, 211-357 (1988).

[17] Y. Kimura, J. Nemoto, M. Shinohara, and M. Niwano, Phys. Status Solid. A. 197, 577-581 (2003).

[18] M. Shinohara, T. Kuwano, Y. Akama, Y. Kimura, M. Niwano, H. Ishida, and R. Hatakeyama, J. Vac. Sci. Technol. A 21, 25-31 (2003).

[19] M. Shinohara, K. Cho, Y. Matsuda, T. Inayoshi, H. Kawazoe, H. Fujiyama, Y. Nitta, and T. Nakatani, J. of Vac. Sci. Technol. A 27, 813-817 (2009).

[20] Z.H. Zhou, E.S. Aydil, R.A. Gottscho, Y.J. Chabal, and R. Reif, J. Electrochem. Soc. 140, 3316-3321 (1993).

[21] M. Shinohara, A. Seyama, Y. Kimura, M. Niwano and M. Saito, Phys. Rev. B 65, 075319 1-7 (2002).

[22] M. Shinohara, Y. Kimura, M. Saito, and M. Niwano, Surf. Sci. 502-503, 96-101 (2002).

[23] H. Ogawa and T. Hattori: IEICE trans. Electron. E75-C, 774-780 (1992).

[24] S. Watanabe: Sur. Sci. 351, 149-155 (1996).

[25] V.A. Burrows, Y.J. Chabal, G.S. Higashi, K. Reghavachari, and S.B. Christma, Appl. Phys. Lett. 53, 998-1000 (1988).

[26] J.I. Pankove, and N.M. Johnson, "Hydrogen in Semiconductors", (Academic Press, San Diego, 1991).

(Received January 18, 2011; Accepted April 29, 2011) 